\title{
Why are primary school children overweight and obese? A cross sectional study undertaken in Kinondoni district, Dar-es-salaam
}

Sijenunu A. Mwaikambo ${ }^{1 *}$ (D) Germana H. Leyna ${ }^{2^{*}}$, Japhet Killewo ${ }^{2}$, Azma Simba ${ }^{1}$ and Thandi Puoane ${ }^{3}$

\begin{abstract}
Background: The world is experiencing an alarming increase in prevalence of childhood obesity. Despite this trend little is known about determinants of childhood obesity in Tanzania. A cross sectional study determined the prevalence and factors associated with overweight and obesity in 1722 children aged 7-14 years (10.9 \pm 1.74$)$ attending primary schools in Dar es Salaam.

Methods: Six public and four private schools were systemically selected from a total of 227 primary schools. Anthropometric measurements (weight and height) were collected using a standard protocol and Body Mass Index (BMI) was calculated. Interviews collected demographic characteristics and lifestyle factors. Multiple logistic regression test was used to assess the influence of independent variables on overweight and obesity while controlling for confounding factors. The level of significance was set at $a=5 \%$.

Results: Of 1, 722 children $10.2 \%$ were overweight and $4.5 \%$ were obese. Overweight and obesity was higher in boys (14.9\%) than girls (14.5\%), higher in children attending private schools (27.7\%) than public schools (5.9\%). Children who walked to and from school were less likely to be overweight or obese than those who used vehicles $(A O R=0.5 ; 95 \% C l: 0.3-0.6 ; p<0.001)$. Those who used private cars or school buses were more likely to be overweight or obese than those who used public transport ( $A O R=2.9 ; 95 \% \mathrm{Cl}: 0.2-0.7 ; p<0.05)$. Computer/video game use were associated with increased risk of overweight and obesity ( $\mathrm{AOR}=1.6 ; 95 \% \mathrm{Cl}: 1.1-2.3 ; p=0.03)$. Lunch provided by schools was associated with increased risk of overweight or obese ( $A O R=6.4,95 \% \mathrm{Cl}=4.2-9.6, p<0.001$ ).

Conclusions: The findings of this study identified a number of behavioural and dietary factors that are related to overweight and obesity. Parents and teachers should encourage children to be physically active by limiting screen time and promoting active transport to and from school to promote health and reduce obesity. Ministry of education needs to formulate/enforce policies that encourage physical activities for school children and regulate quality of foods provided to children at schools.
\end{abstract}

Keywords: Overweight, Obesity, Children, School, Dar es Salaam

\footnotetext{
*Correspondence: sijenunu_aaron@yahoo.com; gerryleyna@yahoo.com

${ }^{1}$ Ministry of Health and Social Welfare, Dar es Salaam, United Republic of

Tanzania

${ }^{2}$ School of Public Health, Muhimbili University of Health and Allied Sciences,

Dar es Salaam, United Republic of Tanzania

Full list of author information is available at the end of the article
} 


\section{Background}

The world is experiencing an alarming increase in prevalence of childhood overweight and obesity [1]. The worldwide prevalence of childhood overweight and obesity increased dramatically from $4.2 \%$ in 1990 to $6.7 \%$ in 2010, [2]. Globally a total of 42 million children under the age of five were estimated to be overweight or obese in 2010 and 92 million were at risk of overweight. A high proportion of this burden (35 million children) was borne by developing countries [2]. The estimated prevalence of childhood overweight and obesity in Africa in 2010 was $8.5 \%$ [2], while that of Asia was $4.9 \%$ and Latin America and Caribbean was $6.9 \%$. This trend is expected to reach $9.1 \%$ (60 million) worldwide and $12.7 \%$ in Africa in 2020 [2].

Studies conducted in many parts of the world have shown physical inactivity including lack of participation in sports activities at school or at home, and less active mode of transport to and from school to be associated with increased risk of overweight and obesity among children [3-5]. Diets high in saturated fats, sugars and refined starch have also been shown to contribute to the increasing overweight and obesity among children and adults [6, 7]. Furthermore, the increase in time spent watching television and playing electronic games partially contributes to the increasing rates of obesity among children [8-14].

However, there is limited information on the magnitude of overweight and obesity in Tanzania given the increase in urbanization, demographic and nutrition transition in the country, particularly in urban areas. The few studies that have been reported have been carried out in rural populations [15], used only the World Health Organization's (WHO) BMI for age percentile and body fat mass measurements [15] or estimated their samples size using an expected prevalence of obesity among women of reproductive age making precision of the sample size estimate questionable [16]. In the current study we used the International Obesity Task Force (IOTF) cut off points for classifying children as overweight or obese to estimate the prevalence of overweight and obesity in Tanzanian school children. The IOTF BMI classification was found to have excellent specificity and sensitivity for overweight cut off points when compared to United Kingdom data and body impedance measure of total fat [17]. In addition, this method was developed using International data, thus allows international comparisons of overweight and obesity in children.

\section{Methods}

\section{Study design, setting and population}

This was a Cross sectional study of children aged 7-14 years attending primary schools in Kinondoni District
Council, Dar es Salaam. This study was conducted in Kinondoni municipality, which is among the three municipalities of Dar es Salaam city; the commercial capital of Tanzania and home for $4.1 \%$ of the total Tanzania mainland population [18]. A majority of the people in the urban part of the municipality engage in selfemployment activities such as trading, fishing and smallscale manufacturing in the informal sector [19].

\section{Sample size \& sampling}

A total of 1, 793 children were estimated using a cluster sampling formula [20]. Using systematic random sampling, six public and four private schools were selected from a total of 227 primary schools (of which 137 were public and 90 were private). The sampling interval for both schools was 23. A total of 180 children were recruited from each of the sampled schools. Systematic random sampling was used to select classes that make up 180 children and all children in a sampled class were included in the study.

\section{Data collection}

A structured questionnaire administered by trained research assistants was used to collect demographic characteristics and lifestyle factors (diet and physical activity) from all children whose parents gave consent and the children assented to participate in the study. The collected demographic data included age, sex, residence, number of siblings, parents' education and occupation. Physical activity data collected were mode of transport to and from school; and television/computer/video game use. Regarding television/computer/video game use, children were asked if they usually used these gadgets where "usually" was defined as at least once every week. Children who reported to "usually" use were asked about days per week and hours per day spent and hours used per week was calculated. The collected diet data included use of full sugar drinks, diet soft drinks, fruit juice, fried food, starch foods, fruits, vegetables, taking breakfast, time heaviest meal of the day taken, and dinner time. Also children were asked if they were given money to buy food at school, the amount of money given and type of food they buy, if they are given lunch at school, type of food given and if they carry lunch boxes to school.

For each child weight in kilograms $(\mathrm{kg})$ was collected using a digital weighing scale that was regularly calibrated to a known weight. Weight measurements were rounded to one decimal place. A Shorr portable measuring board model 420 (Olney, MD 20822, USA) was used to measure height in metres $(\mathrm{m})$. Two measurements were taken and the average was recorded. All measurements were done with children dressed in light clothing with no shoes (Reference Stepwise methodology) [21]. 
BMI $\left(\mathrm{kg} / \mathrm{m}^{2}\right)$ was calculated by dividing the weight $(\mathrm{kg})$ by the squared height $\left(\mathrm{m}^{2}\right)$. Each child was classified as overweight or obese according to the International Obesity Task Force (IOTF) BMI cut off-points for defining overweight and obesity in children between 2 and 18 years. Children with BMI corresponding to a projected BMI of 25 to $<30$ and greater or equal to 30 at age 18 were categorized as overweight and obese respectively. All children with a projected BMI of below 25 at age 18 were categorized as normal weight or underweight [17].

\section{Ethical considerations}

Ethical clearance to conduct the study was granted by the Muhimbili University of Health and Allied Sciences (MUHAS), Research and Publication Ethical Committee. Permission was also sought from the District Executive Director and head teachers of schools that participated in the study. Written consent for children's participation in the study was sought from school authority and parents. All children provided a verbal assent to participate.

\section{Statistical analysis}

Data was analysed using Epi Info software version 3.5.1. Continuous variables were summarized using means and standard deviations and categorical data using frequencies and percentages. Univariate analysis was done for demographic and lifestyle factors. Differences in levels of exposure were statistically tested using Student's $t$ test and Chi square test for continuous and categorical variables, respectively. Odds ratios were estimated to ascertain association between dependent variables (overweight, obesity) and key explanatory variables. Variables were added to the multiple logistic regression models if they had a correlation with BMI at $p<0.2$. Adjusted Odds ratios and their $95 \%$ confidence intervals were reported. All analysis was two-tailed at $\alpha=5 \%$.

\section{Results}

A total of 1722 children aged $7-14$ yeas $(10.9 \pm 1.74)$ participated in the study, a response rate of $96 \%$. Table 1 shows background characteristics of children who participated in the study and their Body Mass Index. Of 1722 children who participated, 175 (10.2\%) were overweight and $78(4.5 \%)$ were obese. Among the girls 98 (10.4\%) were overweight and 39 (4.1\%) were obese while $77(9.9 \%)$ and 39 (5\%) of the boys were overweight and obese respectively. Overweight and obesity was more prevalent in children who attended private primary schools, 18.2 and $9.5 \%$ respectively $(p<0.001)$. Prevalence of overweight and obesity was higher among participants who had 1-3 siblings 181 (16.8 \%) (p 0.001); whose parents had secondary and post-secondary education, 157 (17.9 \%) and 164 (20.2 \%) of those whose fathers and mothers had secondary and post secondary education respectively $(p=0.00)$; used private cars/school buses to and from school $139(28.2 \%)(p=0.0001)$, often watched television 228 (15.7\%), $(p<0.001)$, often played computers or video games $132(22.0 \%)(p=<0.0001)$. The prevalence of overweight and obesity was lower among children who reported usually walking to and from school, 103 (9.3\%) compared to those who reported did not, 150 $(24.6 \%)$ (p 0.00) as shown in Table 1.

\section{Factors associated with overweight and obesity}

Children who reported living with three or less siblings were more likely to be overweight or obese than children living with more siblings $(\mathrm{COR}=1.6,95 \% \mathrm{CI}=1.2-2.2$, p 0.001). Children whose fathers had secondary or post secondary education were more likely to be overweight or obese than children whose fathers had no formal education or had primary education $(\mathrm{COR}=2.8,95 \% \mathrm{CI}=$ $1.8-4.5, p<0.001)$. Similarly children whose mothers had secondary or post secondary education were more likely to be overweight or obese than children whose mothers had no formal or primary school education $(\mathrm{COR}=3.6,95 \% \mathrm{CI}=2.4-5.6, p<0.0001)$.

Children who reported walking to and from school were less likely to be either overweight or obese than those who reported using other means of transport $(\mathrm{COR}=0.3,95 \% \mathrm{CI}=0.2-0.4, p<0.0001)$. Children who reported using school bus or private cars were 4.2 times more likely to be overweight or obese than those who reported using public transport $(\mathrm{COR}=4.2,95 \%$ $\mathrm{CI}=1.9-8.9, p<0.0001)$.

Children who reported watching television were 1.9 times more likely to be overweight or obese than those who did not normally watch television. Children who reported to normally watch television $(n=1449)$, reported to watch for $0.2-105 \mathrm{~h}$ per week $(8 \mathrm{~h} \pm 10.3)$. Those who watched television for more than $14 \mathrm{~h}$ per week were more likely to be overweight or obese than those who reported watching for $14 \mathrm{~h}$ or less per week $(\mathrm{COR}=$ 1.97, $95 \% \mathrm{CI}=1.4-2.9, \mathrm{p}$ 0.0003). Mean time spent watching television per week was almost the same for girls $(7.9 \mathrm{~h} \pm 10.89)$ and boys $(8.2 \mathrm{~h} \pm 9.54)$. Similarly mean time for age group 11-14 years $(7.49 \pm 9.44)$ was almost the same as age group $7-10$ years $(8.87 \pm 11.51)$.

Computer use was reported by 576 (33.4\%) children. Mean time of using computers was $5.4 \mathrm{~h}$ per week \pm 7.96. Mean time for girls was $5.75 \pm 8.74$ and for boys was $4.97 \pm 7.11$. Mean time for age group 11-14 years was $4.71 \pm 7.02$ and for age group 7-10 years was $6.28 \pm$ 9.07. Children who reported often using computers for more than six hours per week were more likely to be overweight or obese than those who reported spending less time on computers (COR $=1.6,95 \%$ $\mathrm{CI}=1.1-2.5, \quad p<0.05)$. Similarly, respondents who 
Table 1 Background characteristics and body mass index of children

\begin{tabular}{|c|c|c|c|c|c|c|}
\hline \multirow[t]{3}{*}{ Characteristics } & No of subjects & $\begin{array}{l}\text { Normal and } \\
\text { underweight }\end{array}$ & $\begin{array}{l}\text { Overweight } \\
\text { (BMI } 25-<30)\end{array}$ & $\begin{array}{l}\text { Obese } \\
(\mathrm{BMI}>=30)\end{array}$ & $\begin{array}{l}\text { Overweight/ } \\
\text { obese }\end{array}$ & \multirow[t]{3}{*}{$p$-value* } \\
\hline & \multirow[t]{2}{*}{$(n=1722)$} & $(n=1469)$ & $(n=175)$ & $(n=78)$ & $(n=253)$ & \\
\hline & & n (\%) & n (\%) & n (\%) & n (\%) & \\
\hline \multicolumn{7}{|l|}{ Gender } \\
\hline Girls & 943 & $806(85.5)$ & $98(10.4)$ & $39(4.1)$ & $137(14.5)$ & \multirow[t]{2}{*}{0.82} \\
\hline Boys & 779 & $663(85.1)$ & $77(9.9)$ & $39(5.0)$ & $116(14.9)$ & \\
\hline \multicolumn{7}{|l|}{ Age group (Yrs) } \\
\hline $7-10(9 \pm 0.97)$ & 639 & $536(83.9)$ & 69 (10.8) & $34(5.3)$ & $103(16.1)$ & \multirow[t]{2}{*}{0.21} \\
\hline $11-14(12 \pm 0.93)$ & 1083 & $933(86.1)$ & $106(9.8)$ & $44(4.1)$ & $150(13.9)$ & \\
\hline \multicolumn{7}{|l|}{ Area of residence } \\
\hline Kinondoni & 1684 & 1439 (85.5) & $169(10.0)$ & $76(4.5)$ & $245(14.5)$ & \multirow[t]{2}{*}{0.26} \\
\hline Other & 38 & 30 (78.9) & $6(15.8)$ & $2(5.2)$ & $8(21.0)$ & \\
\hline \multicolumn{7}{|l|}{ School type } \\
\hline Public & 1030 & $969(94.1)$ & $49(4.8)$ & $12(1.2)$ & $61(6.0)$ & \multirow[t]{2}{*}{$<0.001$} \\
\hline Private & 692 & $500(72.3)$ & $126(18.2)$ & $66(9.5)$ & $192(27.7)$ & \\
\hline \multicolumn{7}{|l|}{ Number of siblings } \\
\hline $0-3$ & 1073 & $892(83.1)$ & $126(11.7)$ & $55(5.1)$ & $181(16.8)$ & \multirow[t]{2}{*}{0.001} \\
\hline 4 and more & 649 & $577(88.9)$ & $49(7.6)$ & $23(3.5)$ & $72(11.1)$ & \\
\hline \multicolumn{7}{|l|}{ Father's level of education } \\
\hline Secondary/post secondary & 879 & $722(82.1)$ & $113(12.9)$ & $44(5.0)$ & $157(17.9)$ & \multirow[t]{3}{*}{$<0.001$} \\
\hline Primary/no formal education & 279 & $259(92.8)$ & $14(5.0)$ & $6(2.2)$ & $20(7.2)$ & \\
\hline Don't know & 564 & $488(86.5)$ & $48(8.5)$ & $28(4.9)$ & $76(13.5)$ & \\
\hline \multicolumn{7}{|l|}{ Mother's level of education } \\
\hline Secondary/post secondary & 813 & $649(79.8)$ & $115(14.1)$ & $49(6.1)$ & $164(20.2)$ & \multirow[t]{3}{*}{$<0.001$} \\
\hline Primary/formal education & 413 & $386(93.5)$ & $20(4.8)$ & $7(1.7)$ & $27(6.5)$ & \\
\hline Don't know & 496 & $434(87.5)$ & $40(8.1)$ & $22(4.4)$ & $62(12.5)$ & \\
\hline \multicolumn{7}{|c|}{ Mode of transport to and from school: Walking } \\
\hline Yes & 1112 & $1009(90.7)$ & $79(7.1)$ & $24(2.2)$ & $103(9.3)$ & \multirow[t]{2}{*}{$<0.001$} \\
\hline No & 610 & $460(75.4)$ & $96(15.7)$ & $54(8.9)$ & $150(24.6)$ & \\
\hline \multicolumn{7}{|c|}{ Mode of transport to and from school: Private cars and public transport } \\
\hline Private car or school bus & 493 & $354(71.8)$ & $87(17.6)$ & $52(10.5)$ & $139(28.2)$ & \multirow[t]{2}{*}{$<0.0001$} \\
\hline Public transport & 117 & $106(90.6)$ & $9(7.7)$ & $2(1.7)$ & $11(9.4)$ & \\
\hline \multicolumn{7}{|l|}{ Usually watch television } \\
\hline Yes & 1449 & $1221(84.3)$ & $154(10.6)$ & $74(5.1)$ & $228(15.7)$ & \multirow[t]{2}{*}{$<0.001$} \\
\hline No & 273 & $248(90.8)$ & $21(7.7)$ & $4(1.5)$ & $25(9.2)$ & \\
\hline \multicolumn{7}{|l|}{ Usually use computers } \\
\hline Yes & 576 & $440(76.4)$ & $91(15.8)$ & $45(7.8)$ & $136(23.6)$ & $<0.0001$ \\
\hline No & 1146 & $1029(89.8)$ & $84(7.3)$ & $33(2.9)$ & $117(10.2)$ & \\
\hline Usually play video games & & & & & & \\
\hline Yes & 600 & $468(78.0)$ & $87(14.5)$ & $45(7.5)$ & $132(22.0)$ & $<0.0001$ \\
\hline No & 1122 & $1001(89.2)$ & $88(7.8)$ & $33(2.9)$ & $121(10.7)$ & \\
\hline Given money to buy food at sch & & & & & & \\
\hline Yes & 1232 & $1087(88.2)$ & $101(8.2)$ & $44(3.6)$ & $145(11.8)$ & $<0.0001$ \\
\hline No & 490 & $382(77.9)$ & $74(15.1)$ & $34(7.0)$ & $108(22.1)$ & \\
\hline
\end{tabular}


Table 1 Background characteristics and body mass index of children (Continued)

\begin{tabular}{|c|c|c|c|c|c|c|}
\hline \multicolumn{7}{|l|}{ Amount of money given } \\
\hline$<=1000$ Tshs $(<=0.5$ USD) & 1144 & $1018(88.9)$ & $88(7.7)$ & $38(3.3)$ & $126(11.0)$ & \multirow[t]{2}{*}{0.008} \\
\hline$>1000$ Tshs (>0.5USD) & 88 & $70(79.5)$ & $12(13.6)$ & $6(6.8)$ & $18(20.5)$ & \\
\hline \multicolumn{7}{|l|}{ Given food to take to school } \\
\hline Yes & 242 & $194(80.2)$ & $31(12.8)$ & $17(7.0)$ & $48(19.8)$ & \multirow[t]{2}{*}{0.02} \\
\hline No & 1480 & $1275(86.1)$ & $144(9.7)$ & $61(4.1)$ & $205(13.9)$ & \\
\hline \multicolumn{7}{|l|}{ Given food at school } \\
\hline Yes & 692 & $500(72.3)$ & $126(18.2)$ & $66(9.5)$ & $192(27.7)$ & \multirow[t]{2}{*}{$<0.001$} \\
\hline No & 1030 & $969(94.1)$ & $49(4.8)$ & $12(1.2)$ & $61(5.9)$ & \\
\hline \multicolumn{7}{|l|}{ Drink light sugar soft drinks } \\
\hline Yes & 829 & $683(82.4)$ & $98(11.8)$ & $48(5.8)$ & $146(17.6)$ & \multirow[t]{2}{*}{0.001} \\
\hline No & 893 & $786(88.0)$ & $77(8.6)$ & $30(3.4)$ & 107 (11.9) & \\
\hline \multicolumn{7}{|l|}{ Dinner time } \\
\hline$<=7: 00 \mathrm{PM}$ & 1536 & $1331(86.7)$ & $146(9.5)$ & $59(3.8)$ & $205(13.3)$ & \multirow[t]{2}{*}{0.06} \\
\hline$>7: 00 \mathrm{PM}$ & 186 & $152(81.7)$ & $22(11.8)$ & $12(6.5)$ & $34(18.3)$ & \\
\hline \multicolumn{7}{|c|}{ Usually eat breakfast before going to school } \\
\hline Yes & 1198 & $1023(85.4)$ & $127(10.6)$ & $48(4.0)$ & $175(14.6)$ & \multirow[t]{2}{*}{0.87} \\
\hline No & 524 & $446(85.1)$ & $48(9.2)$ & $30(5.7)$ & $78(14.9)$ & \\
\hline \multicolumn{7}{|l|}{ Drink full sugar soft drinks } \\
\hline Yes & 1356 & $1157(85.3)$ & $137(10.1)$ & $62(4.6)$ & $199(14.7)$ & \multirow[t]{2}{*}{0.96} \\
\hline No & 366 & $312(85.2)$ & $38(10.4)$ & $16(4.4)$ & $54(14.8)$ & \\
\hline \multicolumn{7}{|l|}{ Usually eat vegetables } \\
\hline Yes & 1675 & $1429(85.3)$ & $170(10.1)$ & $76(4.5)$ & $246(14.7)$ & \multirow[t]{2}{*}{0.97} \\
\hline No & 47 & $40(85.1)$ & $5(10.6)$ & $2(4.3)$ & $7(14.9)$ & \\
\hline \multicolumn{7}{|l|}{ Usually drink fruit juice } \\
\hline Yes & 1612 & $1368(84.9)$ & $169(10.5)$ & $75(4.7)$ & $244(15.1)$ & \multirow[t]{2}{*}{$<0.001$} \\
\hline No & 110 & $101(91.8)$ & $6(5.5)$ & $3(2.7)$ & $9(8.2)$ & \\
\hline \multicolumn{7}{|l|}{ Usually eat fruits } \\
\hline Yes & 1693 & $1443(85.2)$ & $174(10.3)$ & $76(4.5)$ & $250(14.8)$ & \multirow[t]{2}{*}{0.49} \\
\hline No & 29 & $26(89.7)$ & $1(3.4)$ & $2(6.9)$ & $3(10.3)$ & \\
\hline \multicolumn{7}{|l|}{ Usually eat fried food } \\
\hline Yes & 1623 & 1389 (85.6) & $163(10.0)$ & $71(4.4)$ & $234(14.4)$ & \multirow[t]{2}{*}{0.19} \\
\hline No & 99 & $80(80.8)$ & $12(12.1)$ & $7(7.1)$ & 19 (19.2) & \\
\hline \multicolumn{7}{|l|}{ Usually eat starch foods } \\
\hline Yes & 1647 & 1407 (85.4) & $169(10.3)$ & $71(4.3)$ & $240(14.6)$ & \multirow[t]{2}{*}{0.52} \\
\hline No & 75 & $62(82.7)$ & $6(8.0)$ & $7(9.3)$ & $13(17.3)$ & \\
\hline
\end{tabular}

${ }^{*} p$ value corresponds to a comparison of prevalence of overweight/obese children among different groups

reported playing video/computer games were more likely to be overweight or obese than children who did not often play video games $(\mathrm{COR}=2.3,95 \% \mathrm{CI}=$ $1.8-3.1, p<0.001)$.

After adjusting for gender, age and school type, having 1-3 siblings, parents with secondary or post secondary education, using private cars or school bus to and from school, and using computers were found to be associated with increased risk of overweight and obesity as shown in Table 2. Walking to and from school was found to be protective against overweight and obesity.

\section{Overweight and obesity and dietary practices}

Table 3 shows that children who were given money to buy food at school were less likely to be overweight or obese than those not usually given money $(\mathrm{COR}=0.5$, $95 \% \mathrm{CI}=0.4-0.6, p<0.0001)$. However among those given money, children who reported to be given 
Table 2 Factors associated with child overweight or obesity

\begin{tabular}{|c|c|c|c|}
\hline \multirow[t]{3}{*}{ Variable } & \multirow[t]{3}{*}{ Categories } & \multicolumn{2}{|c|}{ Overweight/Obese } \\
\hline & & Model 1 & Model 2 \\
\hline & & COR $(95 \% \mathrm{Cl})$ & AOR $(95 \% \mathrm{Cl})$ \\
\hline \multirow[t]{2}{*}{ Number of siblings } & $0-3$ & $1.6(1.2-2.2)^{*}$ & $1.4(1.5-1.9)^{*}$ \\
\hline & 4 and more & 1.0 & 1.0 \\
\hline \multirow[t]{2}{*}{ Father's level of education } & Secondary or post secondary & $2.8(1.8-4.5)^{* *}$ & $2.8(1.7-4.6)^{* *}$ \\
\hline & Primary or no formal education & 1.0 & 1.0 \\
\hline \multirow[t]{2}{*}{ Mother's level of education } & Secondary or post secondary & $3.6(2.4-5.6)^{* * *}$ & $2.74(1.5-4.9)^{* *}$ \\
\hline & Primary or no formal education & 1.0 & 1.0 \\
\hline \multirow[t]{2}{*}{ Mode of transport to and from school: Walking } & Yes & $0.3(0.2-0.4)^{* * *}$ & $0.5(0.3-0.6)^{* *}$ \\
\hline & No & 1.0 & 1.0 \\
\hline \multirow[t]{2}{*}{ Mode of transport to and from school: Other modes of transport } & Private car or school bus & $4.2(1.9-8.9)^{* * *}$ & $2.9(0.2-0.7)^{*}$ \\
\hline & Public transport & 1.0 & 1.0 \\
\hline \multirow[t]{2}{*}{ Usually watch television } & Yes & $1.9(1.2-2.9)^{*}$ & $1.3(0.8-2.1)$ \\
\hline & No & 1.0 & 1.0 \\
\hline \multirow[t]{2}{*}{ Time used to watch television per week } & Above $14 \mathrm{~h}$ & $2.0(1.4-2.9)^{* *}$ & $1.6(1.0-1.5)$ \\
\hline & $14 \mathrm{~h}$ and less & 1.0 & 1.0 \\
\hline \multirow[t]{2}{*}{ Usually use computers } & Yes & $2.7(2.1-3.6)^{* * *}$ & $1.6(1.1-2.3)^{*}$ \\
\hline & No & 1.0 & 1.0 \\
\hline \multirow[t]{2}{*}{ Time used on computers per week } & $>6 \mathrm{~h}$ & $1.6(1.1-2.5)^{*}$ & $1.5(1.1-1.4)$ \\
\hline & $6 \mathrm{~h}$ or less & 1.0 & 1.0 \\
\hline \multirow[t]{2}{*}{ Usually play video games } & Yes & $2.3(1.8-3.1)^{* * *}$ & $1.2(0.8-1.7)$ \\
\hline & No & 1.0 & 1.0 \\
\hline
\end{tabular}

${ }^{*} \mathrm{p}$-value $<0.05$

${ }^{* *} \mathrm{p}$-value $<0.001$

***p-value $<0.0001$

1000 T.shs (0.5 USD) and less per day were less likely to be overweight or obese than those given more than 1000 T.shs per day $(\mathrm{COR}=0.49,95 \% \mathrm{CI}=0.3-0.9, p<$ $0.001)$.

Children who usually took food to school were more likely to be overweight or obese than those who did not take food to school $(\mathrm{COR}=1.5,95 \% \mathrm{CI}=1.1-2.2, \mathrm{p}$ 0.02). The majority $225(92.7 \%)$ of the children who took food to school reported taking chips, burgers and doughnuts. Similarly children who were given lunch at school were more likely to be overweight or obese than those who were not given lunch at school $(\mathrm{COR}=6.1$, $95 \% \mathrm{CI}=4.5-8.3, p<0.001)$. All four private schools that participated in the study provide lunch to their students while public schools do not provide lunch. Food provided to students is mostly starch (Rice, Chips) and protein (Beef, beans) in all the four private schools.

Children who reported often drinking light sugary soft drinks were more likely to be overweight or obese than those who did not report often drinking light sugary soft drinks $(C O R=1.6,95 \% \mathrm{CI}=1.2-2.1$, p 0.001). Children who reported eating dinner before 7:00 PM were less likely to be overweight or obese than those who reported eating dinner after 7:00 PM $(\mathrm{COR}=0.61,95 \% \mathrm{CI}=0.4-$ $0.9, p<0.001)$. Drinking fruit juice, eating fruits, eating fried food and eating starchy foods were not significant predictors of overweight and obesity as shown in Table 3.

After adjusting for gender, age and school type; eating of breakfast before going to school, and being given money to buy food sold at school was found to be protective against overweight or obesity as shown in Table 3 . Provision of lunch at school was found to be a risk factor for overweight or obesity.

\section{Discussion}

This study revealed that $14.7 \%$ of primary school children in Kinondoni district were either overweight or obese. Our findings on prevalence of overweight (10.2 \%) concur with findings from a study conducted in 2010 to determine the prevalence of overweight and obesity among children aged 6-12 years in Dodoma and Kinondoni municipalities which reported prevalence of overweight among children in Kinondoni municipality to be $10.7 \%$. However this study reported the prevalence of obesity for children in Kinondoni municipality to be 
Table 3 Association between children's dietary practices and overweight or obesity

\begin{tabular}{|c|c|c|c|}
\hline \multirow[t]{3}{*}{ Dietary practices } & \multirow[t]{3}{*}{ Categories } & \multicolumn{2}{|c|}{ Overweight/Obese } \\
\hline & & Model 1 & Model 2 \\
\hline & & COR $(95 \% \mathrm{Cl})$ & AOR $(95 \% \mathrm{Cl})$ \\
\hline \multirow[t]{2}{*}{ Given money to buy food at school } & Yes & $0.5(0.4-0.6)^{* * *}$ & $0.7(0.5-0.9)^{*}$ \\
\hline & No & 1.0 & 1.0 \\
\hline \multirow[t]{2}{*}{ Amount of money given } & $<=1000(<=0.5$ USD $)$ & $0.5(0.3-0.9)^{* *}$ & $0.9(0.5-1.6)$ \\
\hline & $>1000$ (>0.5USD) & 1.0 & 1.0 \\
\hline \multirow[t]{2}{*}{ Given food to take to school } & Yes & $1.5(1.1-2.2)^{*}$ & $2.0(0.6-1.5)$ \\
\hline & No & 1.0 & 1.0 \\
\hline \multirow[t]{2}{*}{ Given food at school } & Yes & $6.1(4.5-8.3)^{* *}$ & $6.4(4.2-9.6)^{* *}$ \\
\hline & No & 1.0 & 1.0 \\
\hline \multirow[t]{2}{*}{ Drink light sugar soft drinks } & Yes & $1.6(1.2-2.1)^{*}$ & $1.0(0.7-1.5)$ \\
\hline & No & 1.0 & 1.0 \\
\hline \multirow[t]{2}{*}{ Dinner time } & $<=7: 00 \mathrm{PM}$ & $0.6(0.4-0.9)^{* *}$ & $0.4(0.5-0.8)^{* *}$ \\
\hline & $>7: 00$ PM & 1.0 & 1.0 \\
\hline \multirow[t]{2}{*}{ Usually eat breakfast before going to school } & Yes & $0.9(0.7-1.3)$ & $0.7(0.5-0.9)^{*}$ \\
\hline & No & 1.0 & 1.0 \\
\hline \multirow[t]{2}{*}{ Drink full sugar soft drinks } & Yes & $1.0(0.7-1.4)$ & \\
\hline & No & 1.0 & \\
\hline \multirow[t]{2}{*}{ Usually eat vegetables } & Yes & $1.0(0.4-2.2)$ & \\
\hline & No & 1.0 & \\
\hline \multirow[t]{2}{*}{ Usually drink fruit juice } & Yes & $2.0(0.9-4.0)$ & \\
\hline & No & 1.0 & \\
\hline \multirow[t]{2}{*}{ Usually eat fruits } & Yes & $1.5(0.5-5.0)$ & \\
\hline & No & 1.0 & \\
\hline \multirow[t]{2}{*}{ Usually eat fried food } & Yes & $0.7(0.4-1.2)$ & $0.8(0.4-1.5)$ \\
\hline & No & 1.0 & \\
\hline \multirow[t]{2}{*}{ Usually eat starch foods } & Yes & $0.8(0.4-1.5)$ & \\
\hline & No & 1.0 & \\
\hline
\end{tabular}

*p-value $<0.05$

**p-value $<0.001$

***p-value $<0.0001$

$11.8 \%$ [15]. Our findings are also comparable to the prevalence of overweight and obesity in some developing and developed countries such as South Africa where $16 \%$ of children aged 6-13 years were reported to be overweight and obese [22], and in Norway where a prevalence of $13.8 \%$ was reported among children aged $2-19$ years) [23] and in France with a prevalence of $15.2 \%$ among children aged 3-14 years [24]. This is a serious public health problem given its established link to chronic health problems during childhood and adulthood [25-29].

The high prevalence of overweight and obesity of primary school children in Kinondoni is attributed to factors assessed by our study but also to other determinants of overweight/obesity such as policies that may play a role in childhood obesity such as school policies (e.g., school canteens, play grounds, inclusion of sports hours in school curricular). Other factors include inadequate availability of pavements for pedestrians, paths for bicycling, and public playgrounds for children, which is a big problem for all major cities in Tanzania including Dar es Salaam.

Our study identified several factors related to dietary and behaviour practices to be associated with overweight or obesity. For example, children who walked or used public transport to and from school were less likely to be overweight or obese than those who were driven by private cars or used school buses. Walking or using public transport to and from school is part of being physically active. Children who use public transport normally walk to and from bus stops, which are sometimes at a distance from their homes or schools. Children who are driven by private cars or use schools buses are picked up 
from home or at school bus stops very close to their homes. Other studies [3-5] conducted in Europe and South America have shown that active form of transport to and from school is associated with decreased risk of overweight and obesity.

Overweight and obesity was also higher among respondents who spent long hours watching television, and playing computer and video games. Studies that examined sedentary habits in children have reported strong association between television watching and obesity $[5,7,8]$. Studies that examined the relationship between the time spent on computers and obesity yielded contradictory findings. For example, a number of studies found no relationship between computer usage and obesity [7, 9-11], while studies undertaken among Portuguese and Brazilian youth found that obesity was related to computer time and not television time in $[5,12]$.

Children who carried lunch to school; those given lunch at school and those who drank light sugary drinks were likely to be overweight or obese. Children who bought food or drinks at school were less likely to be overweight compared to those who either brought own lunch or ate lunch from school. This could be explained by the fact that most of those who carried money to school were given just enough to buy few snacks and those who were given little amount of money were mostly from families with lower SES and attending public schools. Another possible explanation is that whatever food or drinks bought from school was counteracted by the effect of children being physically active including active mode of transport to and from school. On the other hand children who carried a larger amount of money ( $>1000$ Tshs) ( $>0.5$ USD) to school were more likely to be obese and were mostly attending private schools. This could be due to the fact that food served/sold to children in Private schools mainly consisted of refined carbohydrates with little or no fruits and vegetables. The type of lunch provided coupled with sedentary lifestyle in most private school children could be a reason for the higher prevalence of overweight and obesity among these children.

Our study also revealed that children who often ate breakfast before going to school were less likely to be overweight or obese. This finding confirms the findings of other studies which found that skipping breakfast was associated with obesity among children living in developed $[28,30]$ and developing $[31,32]$ countries. Surprisingly, eating fried and starchy foods were found to be associated with decreased risk of obesity. These findings were not anticipated, given that such dietary practices are expected to increase the risk of childhood obesity in developed countries [28]. It is possible that children who are obese reduce their intake of unhealthy foods to cut down weight. Another possible explanation is that overweight or obese respondents may have underreported the types of food so as to paint a picture of consuming a healthy diet.

Children with three or less siblings were at a greater risk of being overweight or obese than those with a higher number of siblings. Similar findings have been reported by another study conducted in Norway [23]. Overweight and obesity was also higher in children who attended private schools compared to those who attended public schools. This could be attributed to the fact that children who attend private schools come from families with higher social economic status than those who go to public schools. Wealthier families can afford to take their children to school using private cars or school buses. They can also afford electronic recreational games such as computer and video games. This has an impact children's level of physical activity.

There are a number of limitations of this study that need to be pointed out. An obvious limitation is its cross - sectional nature which precludes statements of cause and effect. This becomes especially limiting when interpreting associations that could have two legitimate pathways such as reverse association between obesity and walking to school. Walking to school may have a protective effect on development of obesity or it may simply be that obese children prefer to be driven to school. Also as we pointed out earlier some dietary practices did not give anticipated results. This could be due to the fact that overweight and obese children might be cutting down on unhealthy foods and eating more of health foods to lose weight. Thus findings need to be treated with caution.

Another limitation is that puberty, ethnicity and genetic factors that could have an effect on obesity were not assessed. Given the wide age range of our sample it is likely that puberty and other mentioned factors played a role in the onset of overweight and obesity.

In addition, though questions were designed to be age appropriate we cannot rule out the possibility of recall bias and difficulty in comprehending questions in younger children. To overcome this limitation some of the information provided by much younger children was validated against school records where applicable. Furthermore some younger children failed to answer some of the questions a fact that can have an effect on the measure of association calculated.

Another limitation is that information on the amount of food usually consumed was not collected. Given that staple food for most families in Tanzania is starch (rice, ugali-meal made from maize flour, bananas etc.) this information would have been instrumental in assessing the effect of type of food taken on obesity. 


\section{Conclusion}

This study demonstrates that a significant proportion of primary school children in Kinondoni district are either overweight or obese.

Factors related to overweight or obesity were lack of physical activity and unhealthy dietary practices at home and at school. It is therefore recommended that parents and teachers should encourage children to be physically active while at school and at home to reduce rates of obesity in children. Schools/teachers can help children to be physically active by limiting screen time, promoting active transport to and from school and giving preference to outdoor games over video games. Ministry of education needs to formulate/enforce policies that encourage physical activities for school children and regulate quality of foods provided to children at school.

\section{Competing interests}

The authors declare that they have no competing interests.

\section{Authors' contributions}

SA conceived study, collected data and prepared first draft of manuscript, JK and AS helped in writing the study proposal and report. GL conceived the study, reviewed draft manuscript, TP reviewed draft manuscript. All authors read and approved the final manuscript.

\section{Acknowledgement}

We would like to thank African Field Epidemiology Network (AFENET) who funded the study and all study participants for consenting to take part in the study. AFENET is a Network of public health training institutions in Africa that seeks to strengthen manpower to enhance health systems on the continent.

\section{Author details}

${ }^{1}$ Ministry of Health and Social Welfare, Dar es Salaam, United Republic of Tanzania. ${ }^{2}$ School of Public Health, Muhimbili University of Health and Allied Sciences, Dar es Salaam, United Republic of Tanzania. ${ }^{3}$ School of Public Health, University of the Western Cape, Bellville, South Africa.

Received: 1 August 2015 Accepted: 10 December 2015

Published online: 21 December 2015

\section{References}

1. World Health Organization. Obesity: preventing and managing the global epidemic. 2000. http://www.who.int/nutrition/publications/obesity/WHO_ TRS 894/en/ (2000). Accessed 10 June 2011.

2. Onis M, Blössner M, Borghi E. Global prevalence and trends of overweight and obesity among preschool children. Am J Clin Nutr. 2010:92:1257-64.

3. Pabayo R, Gauvin L, Barnett TA, Nikiema B, Seguin L. Sustained active transport is associated with a favourable body mass index trajectory across the early school years: findings from the Quebec Longitudinal study of child development birth cohort. Prev Med J. 2010;50(1):59-64.

4. Singh AS, Chinapa MJ, Brug J, Kremers SP, Visscher TL, Van Mechelin W. Ethinic differences in BMl among dutch adolescents: What is the role of screen viewing, active commuting to school, and consumption of soft drinks and high caloric snacks? Int J Behav Nutr Phys Act. 2009;6:23.

5. Duncan S, Duncan EK, Fernandes RA, Buonani C, Bastos K, Segatto AF, et al, Modifiable risk factors for overweight and obesity in children and adolescents from Sao Paulo, Brazil. BMC Public Health. 2011;11:585. http://www. biomedcentral.com/1471-2458/11/585. Accessed 23 Dec 2011.

6. Nicklas TA, Baranowski T, Cullen KW, Berenson GS. Eating patterns, dietary quality and obesity. J Am Coll Nutr. 2001;20:599-608. http://www. researchgate.net/publication/11585572_Eating_Patterns_Dietary_Quality_ and Obesity. Accessed 20 Oct 2015

7. Huang JY, Qi S. Childhood obesity and food intake. World J Pediatr. 2015; 11(2):101-7. http//www wjpch.com/article.asp?article id=731. Accessed 20 October, 2015
8. Proctor MH, Moore LL, Gao D, Cupples LA, Bradlee ML, Hood MY, et al. Television viewing and change in body fat from preschool to early adolescence: The Framingham children's study. Int J Obes Relat Metab Disord. 2003;27(7):827-33.

9. Mendoza JA, Zimmerman FJ, Christakis DA. Television viewing, computer use, obesity and adiposity in US preschool children. Int J Behav Nutr Phys Act. 2007:4:44

10. Crespo CJ, Smit E, Troiano RP, Bartlett SJ, Macera CA, Andersen RE. Television watching, energy intake, and obesity in US children: results from the third National Health and Nutrition examination survey, 1988-1994. Arch Paediatr Adolesc Med. 2001;155(3):360-5.

11. Futton JE, Wang X, Yore MM, Carlson SA, Galuska DA, Caspersen CJ Television viewing, computer use and BMI among US children and adolescents. J Phys Act Health. 2009;6(1):28-35.

12. Wake $M$, Hesketh $\mathrm{K}$, Waters $\mathrm{E}$. Television, computer use and body mass index in Australia primary school children. J Paediatr Child Health. 2003; 39(2):130-4.

13. Burke V, Beilin L, Durkin K, Stritzke WG, Houghton S, Cameron CA. Television, computer use, physical activity, diet and fatness in Australian adolescents. Int J Paediatric Obes. 2006;1 (4):248-55.

14. Mota J, Ribeiro J, Santos M, Gomes H. Obesity, physical activity, computer use and TV viewing in Portuguese adolescents. Paediatric Exerc Sci. 2006;17: 113-21.

15. Mosha TCE, Fungo S. Prevalence of overweight and obesity among children aged 6-12 years in Dodoma and Kinondoni Municipality, Tanzania. Tanzan Health Res. 2010;12(1):6-16.

16. Kafyulilo A, Mafuniko FN. Prevalence of overweight and obesity among primary school children in Tanzania: experiences from Kinondoni and Njombe districts. 2010. http://papers.ssrn.com/sol3/papers.cfm?abstract_ id=1630534. Accessed 7 Aug 2011.

17. Cole TJ, Bellizzi MC, Flegal KM, Dietz WH. Establishing a standard definition for child overweight and obesity worldwide. Int Survey BMJ. 2000;320(7244): 1240-5.

18. National Bureau of Statistics. Population distribution by age and sex. 2013 http://www.nbs.go.tz (2013). Accessed 14 Dec 2013.

19. National Bureau of Statistics. Tanzania in figures 2012. 2013. http://www.nbs. go.tz (2013). Accessed 14 Dec 2013.

20. Ahmed S. Cluster sampling. Johns Hopkins University: School of hygiene and public health; 2009. http://www.jhsph.edu/courses/ StatMethodsForSampleSurveys. Accessed 7 August, 2011.

21. World health Organization. Chronic diseases and health promotion- STEP wise approach to surveillance. 2008. http://www.who.int/chp/steps/en/ (2008). Accessed on 24 August 2011.

22. Armstrong MEG, Lambert MI, Sharwood KA, Lambert EV. Obesity and overweight in South African primary school children - the Health of the Nation study. S Afr Med J. 2006;96:439-44.

23. Petur BJ, Geir E, Mathieu R. Overweight and obesity in Norwegian children: prevalence and socio demographic risk factors. 2010. http://bora.uib.no/ bitstream/handle/1956/4504/Dr.thesis_Petur\%20Benedikt\%20Juliusson. pdf?sequence=1. Accessed 28 August 2011.

24. Lioret S, Maire B, Volatier $\mathrm{L}$, Charles MA. Child overweight in France and its relationship with physical activity, sedentary behaviour and socioeconomic status. Eur J Clin Nutr. 2007;61(4):509-16. http://www.ncbi.nlm.nih.gov/ pubmed/16988644. Accessed 02 Sept 2011.

25. Must A, Strauss RS. Risks and consequences of childhood obesity. Int J Obes Relat Metab Disord. 1999;23(2):2-11. http://www.ncbi.nlm.nih.gov/pubmed/ 10340798 [Accessed 07 August 2011].

26. Must A. Morbidity and mortality associated with elevated body weight in children and adolescents. Am J Clin Nutr. 1996;63(3):445S-7.

27. Karnik S, Kanekar A. Childhood obesity: a global public health crisis. Int J Prev Med. 2012;3(1):1-7.

28. Duncan JS, Schofield G, Duncan EK, Rush EC. Risk factors for excess body fatness in New Zealand children. Asia Pac J Clin Nutr. 2008; 17(1):138-47.

29. James PT, Leach R, Kalamara E, Shayeghi M. The worldwide obesity epidemic. J Obes Res. 2001;9(4):2285-33S.

30. Deshmukh-Taskar PR, Nicklas TA, O'Neil CE, Keast DR, Radcliffe JD, Cho S. The relationship of breakfast skipping and type of breakfast consumption with nutrient intake and weight status in children and adolescents: The National Health and Nutrition Examination Survey 1999-2006 J Am Diet Assoc. 2010;110(6):869-79. 
31. Maddah M, Nikooyeh B. Factors associated with overweight in children in Rasht, Iran: gender, maternal education, skipping breakfast and parental obesity. Public Health Nutr. 2010;13(2):196-200.

32. Henriquez SP, Doreste AJ, Lainez Sevillano P, Estevez G. Prevalence of obesity and overweight in adolescents from canary islands, Spain; relationship with breakfast and physical activity. Med Clin. 2008;130(16):606-10.

Submit your next manuscript to BioMed Central and we will help you at every step:

- We accept pre-submission inquiries

- Our selector tool helps you to find the most relevant journal

- We provide round the clock customer support

- Convenient online submission

- Thorough peer review

- Inclusion in PubMed and all major indexing services

- Maximum visibility for your research

Submit your manuscript at www.biomedcentral.com/submit 